\title{
Ocular Surface Alterations in Visual Display Terminal Users
}

\author{
OSAMA E. SHALABY, M.D.; AMR M. AWARA, M.D.; HEBA M. SHAFIK, M.D. and \\ DOAA A. EL-SHEIKH, M.Sc.
}

The Department of Ophthalmology, Faculty of Medicine, Tanta University, Tanta, Egypt

\begin{abstract}
Background: Recent years have seen a dramatic increase in the amount of Work performed using Visual Display Terminals (VDTs) the extensive use of VDT has been accompanied by some adverse effects on the human health.
\end{abstract}

Aim of Study: To detect and evaluate ocular surface alterations among visual display terminal users.

Patients and Methods: This prospective observational study was conducted on three hundred VDT users who administered a questionnaire which asked for the duration of using VDT per day, the type of VDT that often used, the position of VDT in relation to the eye and the distance between VDT and the eye, then 68 subjects of them consented to participate in clinical examination to detect any alterations in the ocular surface and the tear film.

Results: The duration of using VDT, the position of VDT in relation to the eye in addition to lighting used during VDT affects the ocular surface. As position of VDT above the eye level was conjoined with the increase in the severity of dry eye this may be because the increase in palpebral aperture and consequently increase the area for tear evaporation.

Conclusions: Using VDT associated with decrease in the blink rate and increase tear evaporation both of which can contribute to dry eye. Also using VDTs for long duration without breaks and positioning of VDT above the eye level both are accompanied by ocular surface alterations and dry eye.

Dim lighted environment and high brightness of VDT screen badly affects the health of the ocular surface and subsequently the functional visual acuity.

Key Words: Visual display terminals (VDTs) - Ocular surface - Dry eye.

\section{Introduction}

VISUAL Display Terminal (VDT) is now a basic feature in many offices, institutions, universities and homes also used in calculating rocery bills, telecommunications, and banking operations [1] .

Correspondence to: Dr. Osama E. Shalaby, The Department of Ophthalmology, Faculty of Medicine, Tanta University, Tatnta, Egypt
VDT includes computers, tablets and other portable information terminals [2].

Various health problems have been associated with the use of VDTs, including visual problems, low back pain, tension headaches, overuse injuries of the hands and wrists (carpal tunnel syndrome) and psychosocial stress [3].

Eye problems include eye discomfort, eyestrain, burning, itching, redness, irritation, blurred vision and dry eye. Other less frequently reported symptoms include double vision, color fringes and reported deterioration of the ability to see fine detail $[4,5]$

Visual symptoms appear to be the most frequent and the most disturbing of VDT associated health problems.

The visual effects of various display characteristics such as screen resolution, glare, display quality, contrast, image refresh rates and flicker, as well as working distances and angles all may contribute to severity of symptoms and ocular surface alterations [6]

\section{Study design:}

Prospective randomized study that was conducted on Visual Display Terminal (VDT) users in the period from January 2016 to January 2017 at both the Ophthalmology Department of Tanta University Hospital and Tanta Ophthalmology Hospital.

\section{Patients and Methods}

Prospective randomized study that was conducted on Visual Display Terminal (VDT) users in the period from January 2016 to January 2017 at both the Ophthalmology Department of Tanta University Hospital and Tanta ophthalmology Hospital. 
A standardized questionnaire was given to 300 VDT users and was analyzed then clinical examination was done for subjects.

\section{Inclusion criteria:}

- Working using VDT for at least past six months.

- Working on the computer for at least 3 hours/ day regularly.

- Healthy subject not complaining of any other ocular disease not related to VDT as chronic glaucoma.

\section{Exclusion criteria:}

- Active ophthalmic infections or inflammation.

- Previous refractive surgery as LASIK or surface ablations.

- Systemic disease as collagen vascular disease or endocrine disease (thyroid disease).

- Age of the subject more than 40 years.

A written questionnaire was used to quantify the prevalence of symptoms in 300 Egyptian VDT users and to determine the effect of risk factors including (gender, age, smoking and hours spent engaged in VDT work) on the health of the ocular surface.

Then patients who consented to do clinical examination underwent ophthalmological examination at Tanta University Hospital (Ophthalmology Department) and/or Tanta Ophthalmology Hospital.

We used a questionnaire that included major questions pertaining to the diagnosis of VDT syndrome and dry eye.

Complete ophthalmological evaluation was done for patients.

We asked for data not included in the questionnaire as:

- Past history of disease: SLE, Rheumatoid Arthritis, Sjogren syndrome and other collagen disease or thyroid disease.

- Other risk factors: e.g undergoing radiation therapy, such as that used to treat cancer, aimed at the eyes.

\section{Patients were subjected to the following:}

-Examination of the eyelids, lid closure and lagophthalmos.

- Slit-lamp examination of eyelids for blepharitis, ectropion, entropion, trichiasis and for punctual patency and position.

\section{Special examination:}

Schirmer I-test:

It was performed using schirmer paper without anesthetic use, taking care not to touch the cornea or eye lashes.

- After 5 minutes the filter paper was removed and the amount of wetting of the paper was measured.

- Considering wetting of less than $10 \mathrm{~mm}$ of the shirmer strip after 5 minutes abnormal value.

\section{Break Up Time test (BUT):}

- It was measured by putting fluerescin impregnated paper strip in the lower conjunctival fornix after wetting with saline.

- Observation with slit lamp using cobalt blue filter was done.

- The time between the last blink and the appearance of the first black spot in the tear film was measured.

- Considering more than 10 seconds for the first dry spot to appear after the last blink is normal value.

\section{Lower tear meniscus height:}

Tear meniscus that less than $1 \mathrm{~mm}$ height considered abnormal.

Staining of the cornea and conjunctiva:

- Fluorescein staining.

- Rose Bengal staining.

- Lissamine green staining.

Scoring systems:

We used Van Bijsterveld system method to grade ocular surface staining: A scoring system that divides the ocular surface into three zones: Nasal bulbar conjunctiva, temporal bulbar conjunctiva, and cornea. Each zone was evaluated on a scale of 0 to 3 , with 0 indicating no staining and 3 indicating confluent staining; the maximum possible score with this system is 9 [7].

Data was tabulated and statistically presented and analyzed using SPSS Version 20.00 program.

\section{Results}

Analysis of the questionnaire obtained from 300 VDT users revealed that:

The most prevalent visual symptoms were eye fatigue (63\%), eye burning (45\%), blurred vision $(34.3 \%)$ and redness $(27.7 \%)$. 
While the most prevalent musculoskeletal symptoms were neck and shoulder pain $(48.3 \%)$ and back pain (3 6.7\%).

In the same time $53 \%$ of subjects complained of headache throughout the day or after using VDT for a long period.

Twenty two subjects complained of tired eyes plus muscloskeletal symptoms without any other visual symptoms.

There is significant correlation between different positions of the center of VDT in relation to the eye and VDT syndrome among the study population with $p$-value $<0.001 *$ as 15 patients with severe VDT syndrome used to use VDT above eye level while only 5 patients of them used to use VDT below eye level with narrower palpebral aperture, may be that is why it was less symptomatic as the increase in the width of the palpebral fissure while looking up above the eye level will cause more evaporation of the tear film and more severe symptoms.

There was a statistically significant correlation between the duration of using VDT and the clinical tests evaluating the ocular surface for dry eye as BUT values, schirmer test and staining, $p$-value was $<0.001 *$.

There was a statistically significant correlation between the severity of VDT syndrome and lighting used while using VDT.

As $80 \%$ of subjects with severe VDT syndrome were illuminating dim light while using VDT while only $20 \%$ of subjects were using good illumination with $p$-value $=(0.025 *)$.

Prevalence of severe dry eye according to staining of the ocular surface was $5.88 \%$. By Fluorescein staining, rose Bengal and Lissamine green (grading using Van Bijsterveld system method) There was a statistically significant correlation between values of BUT and lighting while using VDT. As those who used to use dim light while using VDT were severely affected than those who used well illumination, $p$-value $<0.001 * *$.

Table (1): Symptoms of VDT syndrome (which VDT users complain while using VDT).

\begin{tabular}{lcc}
\hline Symptoms & Number & Percent \\
\hline Eye redness & 83 & 27.7 \\
Eye burning & 135 & 45 \\
Tearing & 38 & 12.7 \\
Eye fatigue & 189 & 63 \\
Headache & 159 & 53 \\
Back pain & 110 & 36.7 \\
Neck and shoulder pain & 145 & 48.3 \\
Blurred near vision & 103 & 34.3 \\
Light sensitivity & 59 & 19.7 \\
Blurred distant vision & 70 & 23.3 \\
Eye itching & 64 & 21.3 \\
Foreign body sensation & 40 & 13.3 \\
Stringy mucous in or around the eye & 17 & 5.7 \\
Scratchy or sandy sensation in the eye & 39 & 13 \\
\hline
\end{tabular}

Table (2): Age distribution of the patients included in the questionnaire.

\begin{tabular}{ll}
\hline Age distribution & \\
\hline Range & $16-40$ \\
Mean \pm SD & $30.02 \pm 5.79$ \\
\hline
\end{tabular}

Table (3): Sex distribution of the patients included in the questionnaire.

\begin{tabular}{lcc}
\hline Sex distribution & $\mathrm{N}$ & $\%$ \\
\hline Female & 149 & 49.7 \\
Male & 151 & 50.3 \\
\hline
\end{tabular}

Table (4): Correlation between the symptoms and different positions of the center of VDT in relation to the eye.

\begin{tabular}{|c|c|c|c|c|c|c|c|c|c|c|}
\hline \multirow{3}{*}{$\begin{array}{l}\text { Position of the } \\
\text { center of VDT } \\
\text { in relation to } \\
\text { the eye }\end{array}$} & \multicolumn{10}{|c|}{ Symptoms } \\
\hline & \multicolumn{2}{|c|}{$\begin{array}{l}\text { No symptoms } \\
\text { (asymptomatic) }\end{array}$} & \multicolumn{2}{|c|}{ Mild } & \multicolumn{2}{|c|}{ Moderate } & \multicolumn{2}{|c|}{ Severe } & \multicolumn{2}{|c|}{ Total } \\
\hline & $\mathrm{N}$ & $\%$ & $\mathrm{~N}$ & $\%$ & $\mathrm{~N}$ & $\%$ & $\mathrm{~N}$ & $\%$ & $\mathrm{~N}$ & $\%$ \\
\hline Above eye level & 2 & 22.2 & 16 & 8.6 & 10 & 13.2 & 15 & 50.0 & 43 & 14.3 \\
\hline Equal to eye level & 5 & 55.6 & 107 & 57.8 & 43 & 56.6 & 10 & 33.3 & 165 & 55.0 \\
\hline Below eye level & 2 & 22.2 & 62 & 33.5 & 23 & 30.3 & 5 & 16.7 & 92 & 30.7 \\
\hline Total & 9 & 100 & 185 & 100 & 76 & 100 & 30 & 100 & 300 & 100 \\
\hline $\begin{array}{l}\text { Chi-square: } \\
\chi^{2} \\
p \text {-value }\end{array}$ & & & & & $\begin{array}{r}36.7 \\
<0.00\end{array}$ & & & & & \\
\hline
\end{tabular}


Table (5): Correlation between the severity of the symptoms and lighting used while using VDT.

\begin{tabular}{|c|c|c|c|c|c|c|c|c|c|c|}
\hline \multirow{3}{*}{ Light } & \multicolumn{10}{|c|}{ Symptoms } \\
\hline & \multicolumn{2}{|c|}{$\begin{array}{l}\text { No symptoms } \\
\text { (asymptomatic) }\end{array}$} & \multicolumn{2}{|c|}{ Mild } & \multicolumn{2}{|c|}{ Moderate } & \multicolumn{2}{|c|}{ Severe } & \multicolumn{2}{|c|}{ Total } \\
\hline & $\mathrm{N}$ & $\%$ & $\mathrm{~N}$ & $\%$ & $\mathrm{~N}$ & $\%$ & $\mathrm{~N}$ & $\%$ & $\mathrm{~N}$ & $\%$ \\
\hline Dim light & 5 & 55.6 & 96 & 51.6 & 37 & 48.7 & 24 & 80.0 & 162 & 54.0 \\
\hline Bright light & 4 & 44.4 & 89 & 48.1 & 39 & 51.3 & 6 & 20.0 & 138 & 46.0 \\
\hline Total & 9 & 100.0 & 185 & 100 & 76 & 100 & 30 & 100.0 & 300 & 100.0 \\
\hline $\begin{array}{c}\text { Chi-square: } \\
\chi^{2} \\
p \text {-value }\end{array}$ & \multicolumn{10}{|c|}{$\begin{array}{l}9.369 \\
0.025^{*}\end{array}$} \\
\hline
\end{tabular}

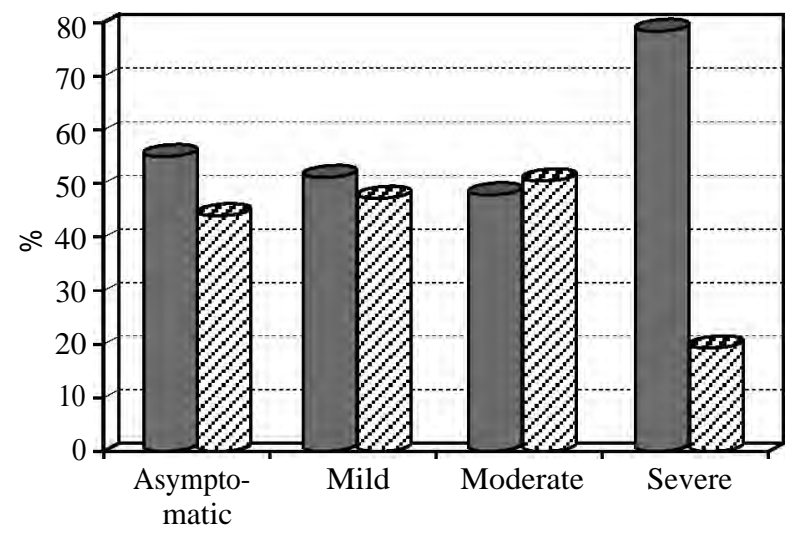

Dim light $\quad Q 2$ Bright light

Fig. (1): Correlation between the severity of the symptoms and lighting used while using VDT.

\section{Discussion}

There has been a dramatic increase in the amount of work undertaken using Visual Display Terminals (VDTs) and this has resulted in an increase in dry eye in the younger population.

VDTs affect general health of its users. Visual and musculoskeletal symptoms are the most disturbing in addition to stress and psychosocial problems [2].

In our study the most prevalent visual symptoms were eye fatigue (63\%), eye burning (45\%), blurred vision $(34.3 \%)$ and redness $(27.7 \%)$ in the same time $53 \%$ of subjects complained of headache throughout the day or after using VDT for a long period.

Redness in our study was reported in $(27.7 \%)$ of the study population while Logaraj M., et al., [8] in their study redness was reported in about $13.9 \%$ of the medical and $23.3 \%$ of engineering students. In contrast, higher prevalence of $40.2 \%$ and $40.7 \%$ symptom of redness was reported by Shrivastava et al., [9] and Talwar et al., [1] among computer professional respectively.

Eye burning was reported in our study in about (45\%) of the study population while Logaraj, et al., [8]. In their study nearly $32.3 \%$ of medical students and $42.8 \%$ of engineering students reported burning sensation. Lower prevalence of $28.9 \%$ was reported by Talwar et al., [1] while Sen and Richardson [10], reported 55\% among undergraduates. Similar finding of $54.6 \%$ of prevalence of burning sensation was reported by Costa et al., [11], among call center workers in Brazil.

Blurred vision was reported in our study in about $(34.3 \%)$ of the study population while Logaraj, et al., [8]. In their study nearly $16.4 \%$ of medical students and $31.6 \%$ of engineering students reported blurring of vision while it was $13.2 \%$ as reported by Talwar et al., [1] .

Rosenfield [12] had reported in his study, a significant difference in the median score with regard to blurred vision during the computer task compared to with a hard copy printout of the material.

In our study $53 \%$ of subjects complained of headache while Logaraj, et al., [8] in their study about $43.3 \%$ of medical and $45 \%$ of engineering students reported headache. Lower prevalence of $29.9 \%$ was reported by Talwar et al., [1], while Sen and Richardson, [10] reported $61 \%$ complained of headache among undergraduates.

Kesavachandran et al., [13] reported $17 \%$ of the employees at information technology suffered from headache. 
In the current study $10 \%$ of patients diagnosed as dry eye according to the symptoms mentioned in the questionnaire while clinical tests of dry eye revealed that $8.09 \%, 5.88 \%$ of patients were diagnosed as severe dry eye according to TBUT, schirmer test respectively, while $59.5 \%, 66.1 \%$ of patients were diagnosed mild or moderate dry eye according to TBUT and staining of the ocular surface respectively.

This correlates with the study made by Yokoi $\mathrm{N}$, et al., [14] which revealed that $11.6 \%$ of their study population had definite DED while $54.0 \%$ diagnosed as probable DED.

In contrast Kojima, et al., [15] reported a higher prevalence of definite dry eye in $30.2 \%$ of VDT users while probable DED in $41.9 \%$, the increase in the percentage of definite dry eye may be due to the inclusion of contact lens wearer in their study.

In our current study about $14.3 \%$ (43 subjects) used to use VDT above the eye level, 165 subjects $(55.0 \%)$ used VDT as the same as the eye level, and 92 subjects (30.7\%) used VDT at a level below the eye level. There were a statistically significant correlation between VDT syndrome and the position of VDT in relation to the eye (viewing angle) with more affection for those who used to use VDT above the eye level with $p$-value ${ }^{<0.001 *}$, this correlates with the study of Nakaishi H, et al., [6] which reported more asthenopia and decrease in tear stability with the increase of the viewing angle.

Tsubota and Nakamori, [16] conducted a study on video display terminal users in which they explained that the increase in the viewing angle while using VDT above the eye level would increase the width of the palpebral fissure and hence the exposed ocular surface area which in turn would increase tear evaporation and cause dry eye.

Uchino and associates [5] reported an association between the use of VDTs by Japanese office workers and DED and suggested more prevalence of DED among female subjects, contact lens wearers, and workers who use VDTs for prolonged periods.

In our study 162 subjects (54.0\%) were using VDT with dim lighted environment while 138 subjects $(46.0 \%)$ were at well or bright illuminated environment when they were using VDT, there was a significant correlation between the severity of VDT syndrome and lighting used while using VDT evidenced by the symptoms score, as severe VDT syndrome was reported among those who were illuminating dim light while using VDT with high brightness. $p$-value $=0.025 *$.

Moreover, the clinical examinations showed a statistically significant correlation between the severity of VDT syndrome and lighting as TBUT values, and the tear meniscus height values revealed more ocular surface alterations among those who were using VDT in a dim lighted environment, $p$ value $<0.001 * *$ for both. This correlates with the study of Thomson WD [4] which reported glare and positive after image with increase the brightness of VDT and decrease the illumination of the surrounding environment.

\section{Conclusion:}

The massive increase in VDT manipulation among all strata of society and among different ages becomes an important health issue.

Using VDT associated with decrease in the blink rate and increase tear evaporation both of which can contribute to dry eye.

Using VDTs for long duration without breaks and positioning of VDT above the eye level both are accompanied by ocular surface alterations and dry eye.

Dim lighted environment and high brightness of VDT screen badly affects the health of the ocular surface and subsequently the functional visual acuity.

\section{Recommendations:}

- The ophthalmologist should take care of every VDT user to detect any ocular surface alterations.

- VDT syndrome must be put in mind in every dry eye patient as it may be behind the symptoms of the patient.

- Breaks should be taken during VDT using, short and frequent breaks would be more useful and avoid long continuous durations of VDT using.

- Proper lighting within VDT workstation area will decrease visual fatigue, improve contrast from the screen and reduce glare while ensuring visual comfort.

- The ideal position for VDT is by placing the VDT at a lower height, with the screen tilted upwards this position will decrease the width of the palpebral fissure and hence the exposed ocular surface area can be decreased. 


\section{References}

1- TALWAR R., KAPOOR R., PURI K., et al.: A study of visual and musculoskeletal health disorders among computer professionals in NCR Delhi. Indian J. Community Med., 34: 326-8, 2009.

2- SHARMA A.K. and KHANDEKAR J.: Computer related health problems among information technology professionals in Delhi. Indian J. Community Med., 31: 36-8, 2006.

3- BLEHM C., VISHNU S., KHATTAK A., et al.: Computer vision syndrome: A review. Surv. Ophthalmol., 50: 25362, 2005.

4- THOMSON W.D.: Eye problems and visual display terminals the facts and the fallacies. Ophthal. Physiol. Opt. 18 (2): 111-9, 1998.

5- UCHINO M., SCHAUMBERG D., DOGRU M., et al.: Prevalence of dry eye disease among Japanese visual display terminal users. J. Ophtha. Lmol., 115 (11): 19828, 2008.

6- NAKAISHI H. and YAMADA Y.: Abnormal tear dynamics and symptoms of eyestrain in operators of visual display. Occup. Environ. Med., 56: 6-9, 1999.

7- VAN BIJSTERVELD O.P.: Diagnostic tests in the Sicca syndrome. Arch. Ophthalmol., 82 (1): 10-4, 1969.

8- LOGARAJ M., MADHUPRIYA V. and HEGDE S.: Computer vision syndrome and associated factors among medical and engineering students in Chennai. Ann. Med. Health Sci. Res., 4: 179-85, 2014.
9- SHRIVASTAVA S.R. and BOBHATE P.S.: Computer related health problems among software professionals in Mumbai: A cross-sectional study. Int. J. Health Sci., 1: 74-8, 2012.

10- SEN A. and RICHARDSON S.: A study of computerrelated upper limb discomfort and computer vision syndrome. J. Hum. Ergol. (Tokyo), 36: 45-50, 2007.

11- COSTA S.E., FERREIRA JUNIOR M. and ROCHA L.E.: Risk factors for computer visual syndrome (CVS) among operators of two call centres in São Paulo, Brazil. Work, 41: 3568-74, 2012.

12- ROSENFIELD M.: Computer vision syndrome: A review of ocular causes and potential treatments. Ophthalmic. Physiol. Opt., 31: 502-15, 2011.

13- KESAVACHANDRAN C., RASTOGI S.K., DAS M., et al.: Working conditions and health among employees at information technology-Enabled services: A review of current evidence. Indian J. Med. Sci., 60: 300-7, 2006.

14- YOKOI N., UCHINO M., DOGRU M., et al.: Importance of tear film instability in dry eye disease in office workers using visual display terminals: The Osaka study. American Journal of Ophthalmology, 159 (4): 748-54, 2015.

15- KOJIMA T., IBRAHIM O., WAKAMATSU T., et al.: "The impact of contact lens wear and visual display terminal work on ocular surface and tear functions in office workers." American Journal of Ophthalmology, 152 (6): 933-40, 2011.

16- TSUBOTA K. and NAKAMORI K.: Dry eyes and video display terminals. N. Engl. J. Med., 328: 584-5, 1993.

\section{تغييرات سطح العين عند مستخلمى شاشات العرض المرئية}

$$
\begin{aligned}
& \text { تعد شاشات العرض المرئى الآن سمة آساسية فى العديد من المكاتب، والجامعات كما تستخدم فى المنازل وحسياب فواتير البقالة }
\end{aligned}
$$

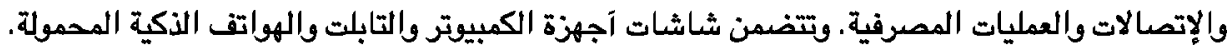

$$
\begin{aligned}
& \text { وتختف المشاكل الصحية الناتجة عن إستخدام شاشات العرض بما في ذلك آجهزة الكمبيوتر ما بين المشاكل البصرية ومشاكل العمود }
\end{aligned}
$$

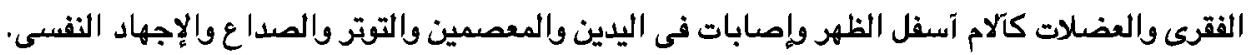

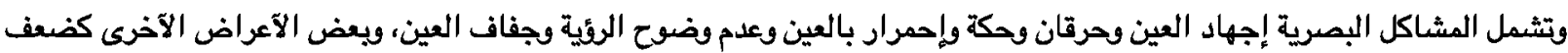

$$
\begin{aligned}
& \text { قوة الإبصار وتغيير فى دقة رؤية الآلوان وتدهود القدرة القين وحلى وفئية التفاصيل الدقيقة. } \\
& \text { والهدف من هذا البحث تحديد التفيرات التى تحدث فى سطح العين نتيجة لإستخدام شاشات العرض المرئى حيث إثتملت هذه الدراسة }
\end{aligned}
$$

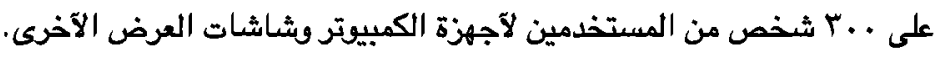

$$
\begin{aligned}
& \text { وكانت آكثر الآعراض البصرية شيوعا بين مستخدمى شاشات العرض المرئية هى إرهاق بالعين وذغللة وحرقان وإحمرار بالعين بينما }
\end{aligned}
$$

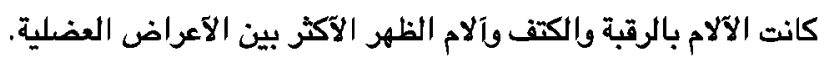

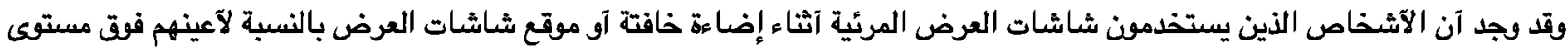

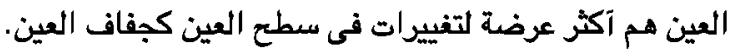

$$
\begin{aligned}
& \text { ويوصى بإستخدام شاشات العرض المرئية لمدد قصيرة متقطعة وآخذ فواصل زمنية فى حالة إستخدامها لفترات طويلة فى وجود إضاءة }
\end{aligned}
$$

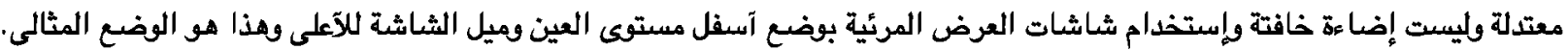

